\title{
Promoción de lectura virtual con estudiantes de secundaria: una intervención en el contexto de la pandemia de COVID en México'
}

\author{
Promotion of Virtual Reading with High School Students - An \\ Intervention in the Context of the COVID Pandemic in Mexico
}

\author{
CAROL MONSERRAT SANTOS GÓMEZ \\ Universidad Veracruzana \\ México \\ carolmonserrat89@gmail.com
}

(Recibido: 05 -OI-2O2I; aceptado: $\left.05^{-0} 5^{-202 I}\right)$

Resumen. Se presenta un proyecto de promoción de lectura en modalidad virtual con estudiantes de secundaria entre II y I4 años. Esta iniciativa tuvo como propósito promover la lectura por placer a través de un club de lectura virtual buscando que los adolescentes la valoraran como un viaje de experiencias y emociones, que contribuyera a su formación como lectores autónomos y letrados. La intervención constó de 18 sesiones extraescolares que se efectuaron a través de las plataformas digitales Facebook, Zoom y WhatsApp, las cuales permitieron comunicación sincrónica y asincrónica, asimismo resolver el problema de las restricciones impuestas por la pandemia de la COVID-19. Se exponen el marco conceptual y referencial, así como los antecedentes y la estrategia metodológica que se basó en el diálogo, la lectura en voz alta y producción de textos. Los resultados muestran que se tuvo un avance significativo en el interés por la lectura, las prácticas lectoras, el desarrollo de la literacidad electrónica, así como en sus habilidades de análisis, crítica y creación literaria.

Palabras clave: lectura por placer; adolescentes; club de lectura; lectura en voz alta; lectoescritura.
Abstract. A project to promote reading in a virtual mode is presented with high school students between II and 14 years of age. The purpose of this initiative was to promote reading for pleasure through a virtual reading club, so that teenagers would value it as a journey of experiences and emotions, which would contribute to their training as autonomous and literate readers. The intervention consisted of 18 extracurricular sessions that were carried out through the digital platforms Facebook, Zoom and WhatsApp, which allowed synchronous and asynchronous communication, and solved as well the problem of the restrictions imposed by the COVID-19 pandemic. The conceptual and referential frameworks are shown, as well as the antecedents and the methodological strategy that was based on dialogue, reading aloud, and text production. The results show that there was a significant advance in their interest in reading, reading practices, the development of electronic literacy, as well as in their analysis, criticism, and literary creation skills.

Keywords: reading for pleasure; teenagers; book club; reading aloud; literacy.

\footnotetext{
${ }^{\text {I }}$ Para citar este artículo: Santos Gómez, Carol Montserrat (2022). Promoción de lectura virtual con estudiantes de secundaria: una intervención en el contexto de la pandemia de COVID en México. Alabe 25 . [www.revistaalabe.com] 


\section{Introducción}

En México muchos estudiantes de educación básica carecen de interés por leer y se enfrentan a problemas de comprensión de textos. Prueba de esto son los bajos resultados que obtuvieron los alumnos de I5 años en el Programme for International Student Assessment [Programa para la Evaluación Internacional de Alumnos] (PISA por sus siglas en inglés) (Salinas et al., 2OI9). Así como los resultados obtenidos por el Módulo sobre Lectura (MOLEC) del Instituto de Estadística y Geografía (INEGI, 2020) los cuales indican que son pocos los textos literarios que se leen. En consecuencia, se han creado una gran cantidad de iniciativas -sobre todo en el sistema educativo oficial- que contribuyan a leer más allá de los fines de alfabetización, convirtiendo al acto de leer en una actividad placentera para que ésta sea un medio de liberación para el progreso y la democratización. Bajo este contexto se ha empezado a hablar de la literacidad, que de acuerdo con Cassany (2OI3) se refiere a las habilidades que permiten a un individuo no sólo decodificar, sino comprender realmente el contenido del texto tanto los mensajes explícitos como los implícitos; incluso se destaca la relevancia de la situación comunicativa y el marco que rodea al escrito, además de que con la entrada del siglo XXI y el crecimiento de la web 2.O ha tomado auge la literacidad electrónica, por lo que ahora se lee y se escribe entre pantallas. Es así como han surgido nuevas formas de comunicación que acompañan al discurso.

Este artículo se asienta en modelo de la investigación-acción y presenta la intervención que realizó la primera autora como parte de su proceso formativo en la Especialización en Promoción de la Lectura, posgrado de la Universidad Veracruzana, bajo la dirección de Álvaro Ricardo De Gasperín Sampieri. A lo largo desde documento se presenta una revisión de los fundamentos conceptuales, los antecedentes, el marco teórico, la estrategia metodológica, los resultados y las conclusiones.

\section{Más allá de la alfabetización: el placer de leer}

Durante el siglo XX en México, la enseñanza de la lectura tuvo propósitos meramente alfabetizadores, aprender a decodificar era lo indispensable en las aulas. Leer se convirtió en un deber, en un verbo imperativo y en una acción exclusiva para fines académicos. Aún en nuestros días estas ideas prevalecen, pero ante las demandas del siglo XXI, Garrido (2OI4) considera que los colegios deberían dejar aún lado esta concepción errónea de centrarse en lo lingüístico y deberían promover la lectura por placer y coadyuvar a que los escolares se aficionen por los libros. Leer por gusto es otorgarles una herramienta de culturización y concientización.

Solé (2009) coincide en que leer debería responder a un anhelo y no a un deber. La lectura es vista como una herramienta de aprendizaje, pero para aprender a leer se requiere contemplar a la lectura como un reto interesante y divertido. Alegóricamente para Colasanti (2OII) leer es un viaje placentero de diversas intensidades. Colasanti (2OII) y 
Garrido (2OI9) coinciden en que para desarrollar este gusto es necesario emplear la lectura en voz alta, especialmente de textos literarios relacionados con tópicos atractivos como lo fantástico, el realismo, aspectos intelectuales o de sentido moral. Garrido (2OI9) resalta que la promoción de la lectura se debería iniciar desde el hogar y después ser reforzada por docentes, bibliotecarios y/o promotores. Quienes necesitan conocer los gustos e intereses de sus hijos, alumnos o miembros del grupo de lectura a fin de seleccionar las lecturas adecuadas. En especial, las escuelas se deben centrar en convertir a los lectores alfabetizados en lectores letrados; al mismo tiempo, alentar a que lean y escriban para diversos fines tanto escolares como personales.

Para definir qué es leer es necesario examinar tres perspectivas: la lingüística, la psicolingüística y la sociocultural. Cassany (2OI3) menciona que no son tres formas distintas de leer sino de concepción. Leer es rescatar el significado literal de los vocablos u oraciones desde el enfoque lingüístico, es sólo un proceso de decodificación. Mientras que la psicolingüística es un proceso cognitivo (Cassany, 2013) o epistémico (Solé, 2009) que demanda de la implicación activa y efectiva de las habilidades de lector que se desarrollan y se perfeccionan con la práctica. A estas destrezas Garrido (2OI4) las llama mecanismos de lectura. Desde la óptica sociocultural no sólo se considera la importancia de lo anterior, sino que leer es un verbo transitivo (Cassany, 20I3): una actividad con heterogéneas, versátiles y dinámicas maneras de comprender el escrito. Tanto texto, escritor y lector son influenciados por su contexto. Por lo que leer es considerada como una práctica social compleja: literacidad.

La expansión del internet y auge de las Tecnologías de la Información y la Comunicación (TIC) han germinado las nuevas literacidades o literacidades electrónicas como las llama Cassany (2OI3). Este concepto no sólo se integra por el discurso en letras sino de fotos, videos, audios, etcétera. El texto adquiere una condición multimodal. Leer en la red ha cambiado los modos de hablar y escribir que requieren de nuevas habilidades de computación, de navegación, verbales, visuales y auditivas. Ha surgido la narración digital: multimodal, remixeada, creación de fanfic o ficción-manía y cooperativa (Cassany, 20I6). Ante esto Garrido (2OI4) dice que existen cuatro tipos de lectores: elemental, utilitario, autónomo y letrado. Los dos primeros se quedan en el nivel básico de decodificación para fines académicos y de trabajo, mientras que el lector autónomo y letrado va más allá porque lee por placer e iniciativa propia, además escribe. Lectura y escritura son un binomio que se integran y se enriquecen para lograr mejores razonamientos.

\section{Clubes de lectura como herramienta para la promoción de la lectura}

El club de lectura es una actividad pensada para que un grupo de individuos con interés en común por leer se reúnan periódicamente con objeto de compartir sus impresiones en torno a textos literarios leídos juntos o no. Convirtiéndose en un espacio comunitario para el intercambio literario, haciendo que el acto solitario y aislado de leer 
se rompa y permita al lector desarrollar sus habilidades comunicativas, así como capacidades de análisis y crítica.

Ante el vertiginoso progreso de las TIC y la irrupción del internet junto con las redes sociales los clubes de lecturas se han tenido que reinventar y las experiencias de lectura se han modificado, ya no sólo se lee en papel sino en pantallas. Ahora se pueden encontrar diversas plataformas de participación abierta o cerrada en línea en donde se trasladan las actividades del club de lectura. De la Cruz González-Cutre et al. (2OI3) distinguen simplemente los clubes de lectura tradicional y clubes de lectura virtual o ciberclub. Mientras que Ferrándiz Soriano (2OI4) realiza una tipología más completa de club de lectura: (I) Clubes de lectura tradicionales: apoyados en reuniones presenciales en la biblioteca y se prestan ejemplares. (2) Club de lectura presencial con complementos de participación virtual: sus reuniones son presenciales en la biblioteca que presta ejemplares y se usan recursos de internet a fin de complementar las sesiones tradicionales. (3) Clubes de lectura virtuales basados en participación textual asincrónica: se apoyan en blogs o grupos mediante redes sociales donde se comentan los libros leídos como Facebook o WhatsApp. (4) Clubes de lectura virtuales en la participación audiovisual sincrónica: usan herramientas o aplicaciones de la web 2.o para efectuar sus reuniones por videoconferencia múltiple como las aplicaciones de Zoom.

El rol del coordinador del club es de vital importancia para gestionar y organizar la comunidad lectora, tanto en clubes presenciales como virtuales. Se encarga de recuperar datos de los miembros, dar seguimiento, llevar estadística, establecer las actividades, realizar las publicaciones, fijar fechas y horarios, facilitar el acercamiento a las lecturas desde una biblioteca o de la nube. Asimismo, debe buscar las estrategias para incentivar la participación de los integrantes del club, mediar en la comprensión del texto literario y guiar a los usuarios si uno de ellos desconoce algún aspecto tecnológico (en el caso de las sesiones virtuales).

\section{Literatura juvenil: los nuevos lectores}

Los textos dirigidos al lector joven son un "pacto ficcional”, es decir, un acuerdo no escrito entre lector y autor para convertir la narración en un proceso ameno y efectivo porque en muchas ocasiones los libros no fueron escritos para este público, sino que son adaptados (Cerrillo Torremocha, 20I5). Además, Lluch (2OI4) indica que la literatura juvenil propone narrativas que usan mecanismos de identificación y un tipo de ideología propuesta para generar consumo de masas y adicción por las obras; al mismo tiempo divierte, educa y contribuye tanto a la formación de la competencia literaria como la lingüística. Según Cerrillo Torremocha (20I5) la literatura juvenil tiene ciertos elementos distintivos en sus historias:

Frecuencia de protagonistas jóvenes, acciones grupales y ambientes juveniles; los personajes adultos intervinientes suelen tener dificultades o sufrir problemas; complicidad con los más desfavorecidos; un notable interés por temas actuales; y una cierta pre- 
ferencia por las aventuras, la fantasía y el amor, aunque no es desdeñable la corriente realista que acerca a los jóvenes a sus conflictos intergeneracionales, sus choques con la realidad o sus problemas específicos. (p.2I5)

Actualmente, los lectores adolescentes son un público inestable y difícil de delimitar. El lector joven requiere enfrentarse a obras más complejas, que exijan mayor esfuerzo y lo mantengan interesado de principio a fin. La literatura juvenil se enfrenta a dos situaciones: ganar lectores o perderlos. La industria de los libros cada día está ávida de lanzar nuevos títulos o sagas. La novedad en la literatura infantil y juvenil crece rápidamente. Se vuelven tendencia; sin embargo, la calidad de muchos de ellos es cuestionable. Existen pocos escritores contemporáneos que valen la pena según Cerrillo Torremocha (20I5) y Colasanti (2OII) como Francisco Hinojosa, Emilio Pascual y Juan Villoro, ya que sus libros logran activar el intertexto lector de los adolescentes; y posiblemente estos los acercarán a la literatura de escritores que no leen frecuentemente como Cortázar, Borges, Conan Doyle, Homero, Kafka, Aristófanes, entre otros; así como a lecturas clásicas juveniles que ocupan un lugar imprescindible en las escuelas y que fueron iniciáticas para muchos. La idea es dirigirlos de una lectura a otras más y así sucesivamente. De ese modo, los jóvenes podrían acceder "a la lectura de los clásicos literarios, recorriendo un itinerario lector en que no hubiera propuestas de lecturas que les resulten distantes, difíciles y, en ocasiones, incomprensibles un itinerario en el que los clásicos deben llegar en el momento apropiado" (Cerrillo Torremocha, 20I5, p.224). Por ello, la literatura juvenil es un medio apto para iniciar y fomentar el gusto por leer.

El adolescente que nació en principios del siglo XXI es un nativo digital: lee y escribe en plataformas digitales de un modo diferente (Diel Schanzembach, 2OIg). Este nativo digital es alguien que realiza múltiples tareas al mismo tiempo, tiene acceso a las nuevas tecnologías y usa el internet como primera opción para distintas finalidades. Este nuevo lector según Cerrillo Torremocha (2005) es un consumidor hipnotizado de las nuevas tecnologías, enganchado al ciberespacio. La tecnologización ha cambiado las formas en que se lee y se escribe, de acuerdo con Cassany (20I6) en la internet se tiene acceso a gran cantidad de textos, pero al mismo tiempo no hay mucha fiabilidad de la información; la escritura toma mayor relevancia, así como su diversificación y remix; los artefactos son cada vez más sofisticados que ofrecen mayores oportunidades y recursos para el autoaprendizaje. En cuanto a la literatura juvenil en la red Cassany (20I6) dice que los jóvenes realizan prácticas vernáculas en las que incorporado narrativas de fanfic o historias realistas y poesía tradicional o libre, ya no sólo son lectores sino autores.

\section{Fundamentos teóricos}

El proyecto se basa epistemológicamente en tres enfoques: la teoría de la recepción literaria, la teoría sociocultural y la teoría del diálogo didáctico mediado, las cuales a su vez se complementan y engrandecen mutuamente. 
La teoría de la recepción literaria recalca la intervención de lector en la situación comunicativa planteada por la obra. Además, considera la relación de la historia literaria entre el texto y autor (Sánchez Vásquez, 2005 y Rodríguez, 20I3). Desde este enfoque la lectura es un proceso dinámico de concreción del discurso el cual es fijado por el autor, pero condicionado por el lector. La relación dialógica entre estos tres elementos que construyen la realidad de la que se realizan inferencias y conexiones sobre un horizonte de expectativas: lo inscrito por el autor y los aportes del autor, y el horizonte extraliterario que surge de los intereses, necesidades y experiencias tanto individuales como colectivas.

Partiendo de que la literatura tiene una función social y es relevante en el mundo real que se mencionó anteriormente, profundizaremos en este punto con la teoría sociocultural. El lector no sólo interpreta o usa una serie de mecanismos cognitivos para su comprensión, sino que para entender el significado del discurso requiere conocimientos previos a fin de crear una Zona de Desarrollo Próximo (ZDP) que le permita comprender el texto (Antunes, 2007). Partiendo de esta idea, Cassany (2013) indica que las palabras toman sentido en un discurso a partir del conocimiento previo del lector y su origen sociocultural. El lector realiza inferencias que le permiten crear una ZDP con objeto de enlazar y construir ideas. Asimismo, el escrito no surge de la nada, parte de la realidad del escritor, reflejando en sus textos sus puntos de vista, visión del mundo, valores y creencias. La relación tripartita entre autor, texto y lector atienden a ámbitos particulares y responden a un complejo constructo social de creencias y normas.

El diálogo es un recurso crucial en los entornos de aprendizaje tanto presencial como digital para alcanzar el pensamiento crítico. Freire (2005) considera que el diálogo es la herramienta para pronunciarse ante el mundo, transformarlo. Es una práctica liberadora que mediante la palabra lleva al individuo a la reflexión y a la acción, a través de este intercambio se da un encuentro se da la creación y recreación de la realidad. Para que realmente se dé el diálogo se requiere una comunicación horizontal entre los sujetos, así como un clima de confianza que les permita pensar, reflexionar y actuar. Conforme la gente socializa con otros, discute los conocimientos, libros, situaciones, problemas o temas en particular se va esclareciendo su conciencia su contexto y surge la visión crítica. Freire (2005) cree que la lectura y discusión de artículos, capítulos de libros y diarios son buenas estrategias para el desarrollo del pensamiento crítico.

Considerando que el proyecto de intervención será virtual es fundamental conocer la dinámica trabajo a distancia. García Aretio (2008) propone la teoría del diálogo mediado que se basa en un modelo de comunicación a través de los medios digitales de la interactividad vertical y horizontal. Aunque tiene un enfoque pedagógico, desde el punto de vista de la promoción de la lectura se puede adaptar a relación entre coordinador- participantes y entre pares. Es importante mencionar que hay cuatro componentes esenciales en todo programa a distancia: docencia (docente), aprendizaje (alumnos), materiales (contenidos programáticos) y comunicación (soportes digitales). Los cuales aterrizando a la promoción de la lectura sería promotor, grupo de intervención, cartografías lectoras y plataformas digitales. 


\section{Antecedentes}

Previo al diseño y ejecución de la intervención se revisaron algunos casos similares en relación con la promoción de la lectura y se encontraron múltiples estudios e investigaciones a nivel internacional y nacional. Para fines de este artículo se indican las iniciativas que más contribuyeron a la metodología de este trabajo. A continuación, a grandes rasgos se indican los elementos más significativos:

(I) Bibbó (20I8) implementado en nivel secundaria con adolescentes argentinos. La autora tomó la red social Facebook como una herramienta que entusiasma más a los estudiantes para el trabajo literario. La modalidad del club de lectura fue presencial con complementos de participación virtual en un grupo cerrado que autodenominaban "El club de la serpiente".

(2) El proyecto de intervención Facebook, un espacio para compartir la lectura realizado por Amar et al. (20I8) en un instituto de educación secundaria en España. En dicha intervención se les dio la oportunidad a los estudiantes de elegir la cartografía lectora y posteriormente compartir a través del diálogo en el aula sobre el libro y debates en Facebook.

(3) El club de lectura llamado "Rompiendo el calendario" creado por Moral y Arbe (20I3) fue dirigido al alumnado que lee y escribe por placer tanto en soportes digitales como en papel o aquellos que tengan inquietudes literarias. El club de lectura fue integrado por docentes y estudiantes de nivel secundaria y bachillerato en España. Algunas de las actividades se hicieron de forma presencial y otras virtuales como: creación literaria, lecturas, participación en eventos de lectura y debates.

(4) El club de lectura "El grito" en la biblioteca pública de Albacete (España) que presenta Prieto García (2OIO) con la intención de atraer a los adolescentes y jóvenes que integraban otros clubes de la biblioteca. Además de las reuniones periódicas presenciales se agregó la participación virtual.

(5) El taller de lectura virtual llamado "La magia de los libros" realizado por Sánchez Sosa (20I8) quien trabajó con profesionales pertenecientes a cuatro oficinas de la Unidad Central de la Universidad Veracruzana con la intención fundamental de promocionar la lectura digital. Se fomentó el diálogo y el debate después de cada sesión presencial y virtual a través del blog. En las sesiones presenciales se hicieron lecturas en voz alta y múltiples dinámicas a fin de estimular la lectura y la creatividad.

(6) López Acosta (20I5) realizó una promoción de la lectura en espacios virtuales con el portal de lectores y lecturas de la Universidad Veracruzana. Los integrantes del taller usaron un blog privado para descargar las lecturas principalmente cuentos y novelas cortas, pudieron comentar sobre las mismas, consultar información extra sobre las lecturas y consultar las dinámicas realizadas.

(7) En el protocolo de especialización de Puc Domínguez (20I5) se presenta una propuesta enfocada al desarrollo de un círculo de lectura con estudiantes de tercer grado entre I3 y i6 años en una escuela secundaria pública en Veracruz, México. Sus inte- 
reses fueron estimular la lectura más allá de las aulas escolares y utilizar a la lectura como una actividad accesible, lúdica y constructiva del ser humano. Además, coadyuvar a una claridad del pensamiento y crecimiento personal.

(8) El trabajo recepcional por García Figueroa (20I6) quien se ocupó de la promoción de la lectura a través de Facebook entre estudiantes de primer y segundo semestre de la Facultad de Contaduría de la Universidad Veracruzana en México. Aunque la red social fue su eje principal para compartir textos del género literario, así como videos e imágenes, libros digitales de literatura y poesía, efectuó algunas reuniones presenciales.

\section{Metodología}

El proyecto de intervención se realizó con estudiantes de la Escuela Secundaria Técnica Industrial No. 98 del municipio de Orizaba, Veracruz. La invitación se realizó a los tres grados de secundaria del I 4 al 24 de septiembre de 2020 a través de la página de Facebook y el sitio web del colegio. Aunque 20 estudiantes se inscribieron a la convocatoria emitida, cuando se inició el grupo se conformó de I5 alumnos entre los II y I 4 años. La promoción de lectura virtual comenzó el 25 de agosto y concluyó el 22 de octubre de 2020 en un horario de martes y jueves de 3:00 a 4:00 pm. El club de lectura contó con I8 sesiones virtuales a través de un grupo privado en la red social Facebook, también se usó Zoom y en algunas sesiones y WhatsApp, como plataformas complementarias para tener mayor interacción sincrónica y asincrónica.

El objetivo general fue promover la lectura por placer con estudiantes de secundaria a través de un club de lectura virtual con el fin de valorarla como un viaje de experiencias y emociones, que les permita poner en práctica la literacidad electrónica, desarrollar la competencia de lectura en voz alta y practicar la lectura dialógica, asimismo identificar las habilidades de análisis, crítica y creación literaria, mediante productos multimodales que contribuyan en su formación como lectores autónomos y letrados.

En cuanto a los objetivos particulares estos fueron: (I) Fomentar entre los estudiantes el interés por la lectura por placer a través de plataformas digitales para la formación de lectores autónomos y letrados. (2) Coadyuvar a la mejora de las prácticas lectoras de los alumnos mediante la lectura en voz alta. (3) Contribuir al desarrollo de la literacidad electrónica de los estudiantes por medio de la lectura digital de textos literarios propios a su edad e intereses. (4) Promocionar las habilidades de análisis y crítica de los textos literarios expresados en sus opiniones, experiencias de vida y emociones a través de actividades de narrativa digital y lectura dialógica en Facebook. (5) Promover el desarrollo las habilidades creativas por medio de diversas producciones literarias multimodales.

La hipótesis de intervención se centró en que: la creación de un club de lectura virtual con estudiantes de secundaria orientado al placer de leer, el análisis y crítica de textos literarios, así como la producción y publicación de sus textos, fortalecerá sus 
competencias como lectores autónomos y podrán a mediano o largo plazo convertirse en lectores letrados.

El club de lectura fue un espacio virtual fundamentado en el modelo de educación a distancia para el intercambio literario de microrrelatos, cuentos y novelas relacionados con la literatura infantil y juvenil, sobre todo con la última. La cartografía lectora se centró en los gustos e intereses de los estudiantes, a fin de complementar se usó la narrativa digital multimodal (videos, imágenes, etcétera) y las técnicas: lectura en voz alta, lectura dialógica, reseñas críticas y ejercicios de escritura creativa. Es relevante mencionar que por el enfoque sociocultural del proyecto se permitió que ellos compartieran textos y decidieran las lecturas de los libros, al mismo tiempo se dio importancia a la respuesta literaria de cada obra.

La evaluación fue cuantitativa y cualitativa contó con tres momentos de valoración: (I) Previa. Se realizó el diagnóstico por medio de la técnica del cuestionario (Figura I) de forma virtual relacionada con los hábitos lectores. (2) Durante. Se llevó un registro de lo que sucede en cada sesión mediante una bitácora que monitoreó la participación de los estudiantes y la efectividad de las actividades. Esta herramienta de observación participativa permitirá a la promotora reflexionar sobre sus intervenciones. (3) Posterior. Implicó una evaluación final en dos aspectos uno se analizó la evolución de la producción de textos (orales u escritos) de los alumnos con rúbricas (Figura 2). Además, una encuesta a fin de conocer su experiencia como participantes en el club de lectura.

\section{Figura I}

Cuestionario del diagnóstico 
La intención de este cuestionario conseguir información sobre tus hábitos de lectura. Tus respuestas son anónimas.

Marca con una " $\mathrm{X}$ ".

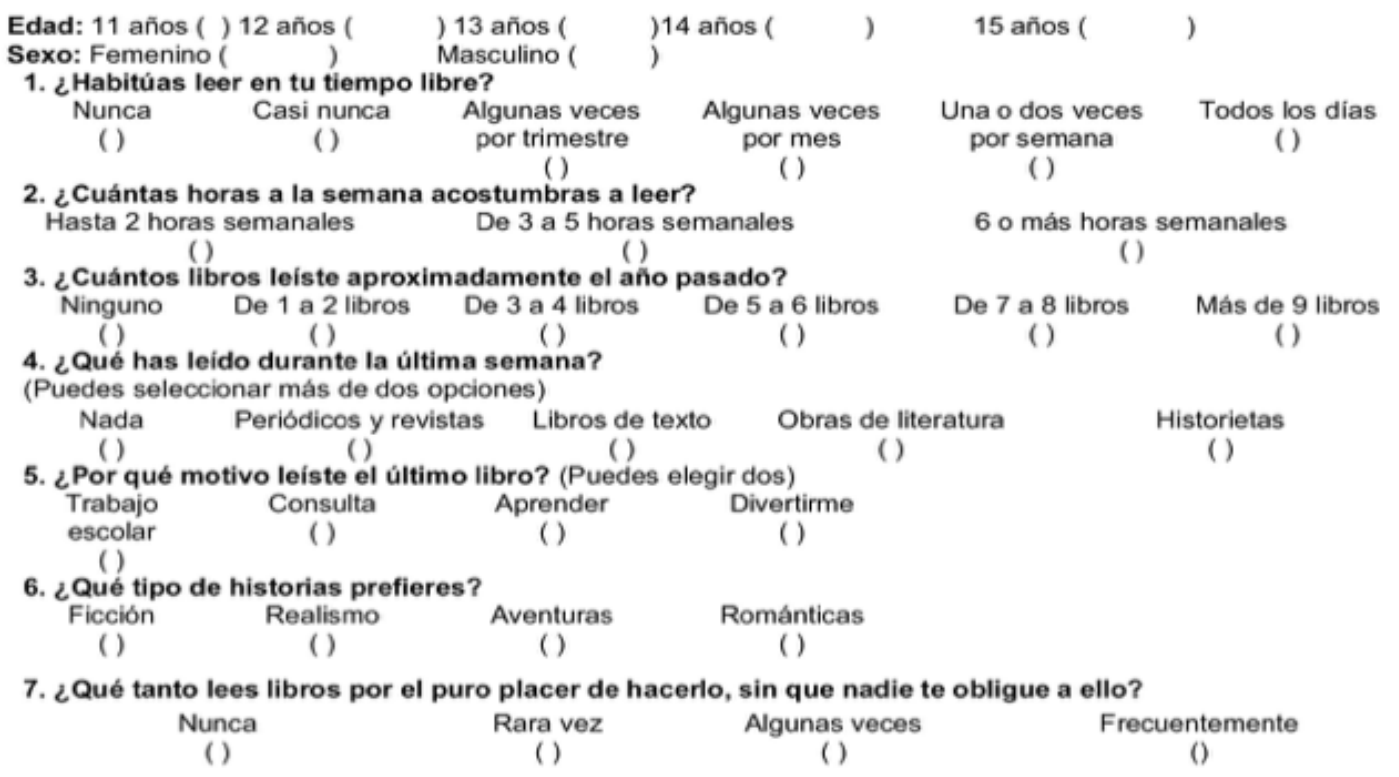

8. Indica el título de tres de tus libros favoritos (no importa que sean infantiles), ¿por qué te gustaron tanto?

9. Indica el titulo de los tres últimos libros que hayas leido.

10. ¿En qué soporte lees? (puedes seleccionar más de uno)
Copias
Libro
Computadora
( )
Celular
11. ¿Te gusta escribir?
( )
( )
Siempre
Casi siempre
$A$ veces
12. ¿Qué tanto escribes alguna vez por el simple placer de hacerlo, más allá de las obligaciones ( del colegio?

Siempre

$$
\text { () }
$$

Casi siempre

( )

( )

13. ¿En qué soporte escribes? (puedes seleccionar más de uno)
Hojas
Libreta y/o cuaderno
Computadora
( )
) ()
()
Celular
( )

( )

\section{Figura 2 \\ Rúbricas usadas al cierre de la intervención}

\begin{tabular}{|c|c|c|c|}
\hline \multicolumn{4}{|c|}{ Rúbrica 1. Evaluar lectura en voz alta } \\
\hline Contiene & $\begin{array}{c}\text { Alto } \\
\text { (3) }\end{array}$ & $\begin{array}{c}\text { Medio } \\
\text { (2) }\end{array}$ & $\begin{array}{c}\text { Bajo } \\
\text { (1) }\end{array}$ \\
\hline Volumen & $\begin{array}{l}\text { La voz se escucha y la lectura es } \\
\text { comprensible. }\end{array}$ & $\begin{array}{l}\text { A veces hay un esfuerzo por } \\
\text { escuchar la voz, no se logra } \\
\text { comprender en su totalidad. }\end{array}$ & $\begin{array}{l}\text { Casi no se escucha y no se logra } \\
\text { entender la mayoría de lo que } \\
\text { dice. }\end{array}$ \\
\hline Fluidez & $\begin{array}{l}\text { Lectura continua sin detenciones ni } \\
\text { dificultades. }\end{array}$ & $\begin{array}{l}\text { A veces existen algunas } \\
\text { reiteraciones o cambios de } \\
\text { palabras. }\end{array}$ & $\begin{array}{l}\text { Lectura silábica o palabra por } \\
\text { palabra, hay muchos errores. }\end{array}$ \\
\hline Entonación & $\begin{array}{l}\text { Respeta los signos de puntuación, } \\
\text { exclamación e interrogación, } \\
\text { realizando las inflexiones correctas. }\end{array}$ & $\begin{array}{l}\text { A veces respeta los signos de } \\
\text { puntuación, exclamación e } \\
\text { interrogación, realizando o no las } \\
\text { inflexiones correctas. }\end{array}$ & $\begin{array}{l}\text { No respeta los signos de } \\
\text { puntuación, exclamación e } \\
\text { interrogación, lectura } \\
\text { monótona. }\end{array}$ \\
\hline
\end{tabular}




\begin{tabular}{|l|l|l|l|}
\hline Contiene & \multicolumn{2}{|c|}{$\begin{array}{c}\text { Avanzado } \\
\text { (3) }\end{array}$} & \multicolumn{1}{|c|}{$\begin{array}{c}\text { Rúbrica 2. Video-reseñas } \\
\text { Progresista } \\
\text { (2) }\end{array}$} \\
\hline Autor & $\begin{array}{l}\text { Explica brevemente quién es, su } \\
\text { nacionalidad, tres obras y dos } \\
\text { datos relevantes. }\end{array}$ & $\begin{array}{l}\text { Explica brevemente quién es, } \\
\text { pero omite: su nacionalidad, tres } \\
\text { obras o dos datos relevantes. }\end{array}$ & $\begin{array}{l}\text { Sólo menciona el nombre del } \\
\text { escritor y omite el reto de la } \\
\text { información o ni siguiera lo } \\
\text { menciona. }\end{array}$ \\
\hline Sinopsis & $\begin{array}{l}\text { Realiza una síntesis de la obra sin } \\
\text { contar el final. }\end{array}$ & Cuenta casi toda la historia. & Cuenta toda la historia. \\
\hline $\begin{array}{l}\text { Comentario } \\
\text { crítico y } \\
\text { recomendación }\end{array}$ & $\begin{array}{l}\text { Analiza en qué contexto surgió la } \\
\text { obra, habla sobre la narrativa. } \\
\text { Argumenta qué le gustó y la } \\
\text { razón por la que recomienda. }\end{array}$ & $\begin{array}{l}\text { Analiza superficialmente qué } \\
\text { contexto surgí la obra, habla } \\
\text { sobre la narrativa. Argumenta } \\
\text { someramente qué le gustó y la } \\
\text { razón por la que recomienda. }\end{array}$ & $\begin{array}{l}\text { No analiza ni argumenta su } \\
\text { opinión respeto a la obra. }\end{array}$ \\
\hline $\begin{array}{l}\text { Comunicación } \\
\text { oral }\end{array}$ & $\begin{array}{l}\text { Su dicción es clara, la voz es } \\
\text { fuerte y fluida. }\end{array}$ & $\begin{array}{l}\text { En algún momento su dicción es } \\
\text { no es tan clara, su voz no es ni tan } \\
\text { fluida ni fuerte. }\end{array}$ & $\begin{array}{l}\text { Su dicción no es clara, ni su voz } \\
\text { fluida ni fuerte. }\end{array}$ \\
\hline
\end{tabular}

\begin{tabular}{|c|c|c|c|}
\hline \multicolumn{4}{|c|}{ Rúbrica 3. Textos narrativos } \\
\hline Contiene & $\begin{array}{l}\text { Avanzado } \\
(3)\end{array}$ & $\begin{array}{c}\text { Progresista } \\
\text { (2) }\end{array}$ & $\begin{array}{l}\text { Novato } \\
\text { (1) }\end{array}$ \\
\hline $\begin{array}{l}\text { Cumple el } \\
\text { propósito } \\
\text { comunicativo }\end{array}$ & $\begin{array}{l}\text { Escribe lo que se solicita ya sea } \\
\text { un cuento, microrrelato o epístola. } \\
\text { Cuenta el inicio, el desarrollo y el } \\
\text { desenlace (abierto o cerrado). }\end{array}$ & $\begin{array}{l}\text { Escribe lo que se solicita ya sea un } \\
\text { cuento, microrrelato o epistola. } \\
\text { Omite alguna de las partes ya sea el } \\
\text { inicio, el desarrollo o el desenlace } \\
\text { (abierto o cerrado). }\end{array}$ & $\begin{array}{l}\text { No escribe lo que se solicita ya sea } \\
\text { un cuento, microrrelato o epístola. } \\
\text { Omite alguna de las partes ya sea el } \\
\text { inicio, el desarrollo y el desenlace } \\
\text { (abierto o cerrado). }\end{array}$ \\
\hline $\begin{array}{l}\text { Relación entre } \\
\text { palabras y las } \\
\text { oraciones }\end{array}$ & $\begin{array}{l}\text { Emplea correctamente los } \\
\text { tiempos verbales, género y } \\
\text { número. }\end{array}$ & $\begin{array}{l}\text { Comete tres o cuatro errores en } \\
\text { tiempos verbales, género y número. }\end{array}$ & $\begin{array}{l}\text { Comete más de cuatro errores en } \\
\text { tiempos verbales, género y número. }\end{array}$ \\
\hline $\begin{array}{l}\text { Uso de los } \\
\text { signos de } \\
\text { puntuación }\end{array}$ & $\begin{array}{l}\text { Utiliza comas, punto y coma, } \\
\text { puntos, dos puntos, guiones, } \\
\text { signos de exclamación e } \\
\text { interrogación adecuadamente. }\end{array}$ & $\begin{array}{l}\text { Omite o coloca inadecuadamente } \\
\text { tres o cuatro comas, punto y coma, } \\
\text { puntos, dos puntos, guiones o } \\
\text { signos de exclamación e } \\
\text { interrogación. }\end{array}$ & $\begin{array}{l}\text { No coloca o utiliza más de cuatro } \\
\text { veces inadecuadamente comas, } \\
\text { punto y coma, puntos, dos puntos, } \\
\text { guiones o signos de exclamación e } \\
\text { interrogación. }\end{array}$ \\
\hline $\begin{array}{l}\text { Uso de reglas } \\
\text { ortográficas. }\end{array}$ & $\begin{array}{l}\text { Uso correcto de tildes, } \\
\text { mayúsculas y minúsculas, evita } \\
\text { confusión de homófonas y } \\
\text { homógrafas. }\end{array}$ & $\begin{array}{l}\text { Uso incorrecto (tres o cuatro veces) } \\
\text { u omisión de tildes, mayúsculas y } \\
\text { minúsculas, confusión de algunas } \\
\text { palabras homófonas y homógrafas. }\end{array}$ & $\begin{array}{l}\text { Uso incorrecto de tildes, } \\
\text { mayúsculas y minúsculas, confunde } \\
\text { las palabras homófonas y } \\
\text { homógrafas. }\end{array}$ \\
\hline $\begin{array}{l}\text { Creatividad y } \\
\text { originalidad }\end{array}$ & $\begin{array}{l}\text { Contiene detalles creativos que } \\
\text { cautiven al lector. Crea imágenes } \\
\text { mentales a partir del texto leído. }\end{array}$ & $\begin{array}{l}\text { Contiene algunos detalles creativos. } \\
\text { Crea algunas imágenes mentales a } \\
\text { partir del texto leído. }\end{array}$ & $\begin{array}{l}\text { No contiene ningún detalle creativo. } \\
\text { No crea imágenes mentales a partir } \\
\text { de lo leído. }\end{array}$ \\
\hline
\end{tabular}

\section{Resultados de la intervención}

Los datos se obtuvieron en las encuestas digitales (Formularios de Google), bitácoras y rúbricas digitales (Word); los más significativos se juntaron en un archivo digital (PowerPoint). Los gráficos se realizaron en el software libre Rstudio; se usaron diversas gráficas de serie de tiempo, histogramas y dendrogramas para la organización de la información. También se realizaron tablas como elemento complementario.

A partir de lo anterior se determinó que el grupo estuvo integrado por I5 estudiantes, nueve de ellos eran los más constantes con las reuniones y actividades, ya fuera en forma sincrónica o asincrónica. Seis alumnos tuvieron participaciones intermitentes por fallas en su conectividad o por el exceso de tareas que tenían de la escuela. Por la virtualidad se podía dar una interacción simultánea o no; sin embargo, los adolescentes preferían mantener una comunicación en tiempo real. Por otro lado, la media de asistencia durante todas las sesiones fue de casi I 4 , mientras que la participación directa fue de cerca de II y la indirecta fue de aproximadamente de tres (Tabla I). Por último, la participación total 
tuvo un mínimo de diez asistentes y máximo de i6 a lo largo de la intervención.

Tabla I

Resumen de estadísticas descriptivas de variables cuantitativas de la bitácora.

\begin{tabular}{|c|c|c|c|c|c|}
\hline Variable/Estadística & Media & Des. Estándar & Mediana & Mínimo & Máximo \\
\hline Reacciones & 64.25 & 32.3 & 62 & 18 & 112 \\
\hline Comentarios & 84.1 & 48.5 & 80 & 13 & 190 \\
\hline Compartieron experiencia & 9.778 & 1.833 & 9.5 & 7 & 15 \\
\hline Participación sincrónica & 10.833 & 1.978 & 10 & 8 & 15 \\
\hline Participación asincrónica & 2.833 & 1.383 & 2.5 & 1 & 6 \\
\hline
\end{tabular}

Las sesiones tuvieron una duración de una hora, en los primeros 30 minutos se realizó la lectura en voz alta y diálogo (escrito u oral) dependiendo la plataforma. El resto del tiempo fue dedicado a la creación literaria. Los comentarios eran usualmente relacionados con los textos leídos o textos realizados por ellos mismos. Durante este diálogo escrito se usaron las reacciones o emoticonos que forman parte de la escritura ideofonemática a la cual de acuerdo con Cassany (20I6) simplifican el código gráfico y crean significados de forma lúdica y creativa para simbolizar estados de ánimo, en este caso representar las emociones que les evocó el texto o el comentario de algún compañero.

Facebook fue empleado como una plataforma central, mientras Zoom y WhatsApp fueron complemento. En Facebook se creó una página del club llamada "Club de lectura 98" y un grupo privado de ese mismo nombre, en este último se realizaban transmisiones en vivo o subían videos, también la investigadora compartía post de sobre los autores o frases literarias, en cuatro ocasiones cuatro alumnos diferentes se animaron a compartir un post. Zoom se usó para socializar la lectura de los libros leídos y WhatsApp, fue usado como medio informativo, para compartir PDF o ligas, así como canal de comunicación entre estudiantes y coordinadora. Por tales motivos, Facebook se usó 94.44 \% (I7) de las sesiones, Zoom se empleó en un 55.55\% (I3) para las reuniones simultaneas y WhatsApp fue utilizado en todas las intervenciones.

La lectura en voz alta fue un elemento clave para la mejora de las prácticas lectoras, así que la investigadora durante iz sesiones leyó en voz alta. Salvo en de la última sesión. Por otro lado, al comienzo de la intervención se evaluó la lectura en voz alta de los estudiantes a través de un video siguiendo la rúbrica de lectura en voz alta que clasificaba la lectura en nivel bajo, medio y alto y al concluir se leyó en voz alta en Zoom en las dos últimas sesiones y los que no pudieron entrar enviaron video y se empleó la misma. En evaluación al inicio de la intervención se conformaron tres grupos: el primero, en nivel 
bajo con 6 alumnos; el segundo, en nivel medio con ocho y en el nivel alto, sólo uno (Figura 3). Al cierre, desapareció el nivel bajo, quedando siete estudiantes en nivel alto y ocho en nivel medio (Figura 4).

Figura 3

Dendrograma de nivel de lectura en voz alta.

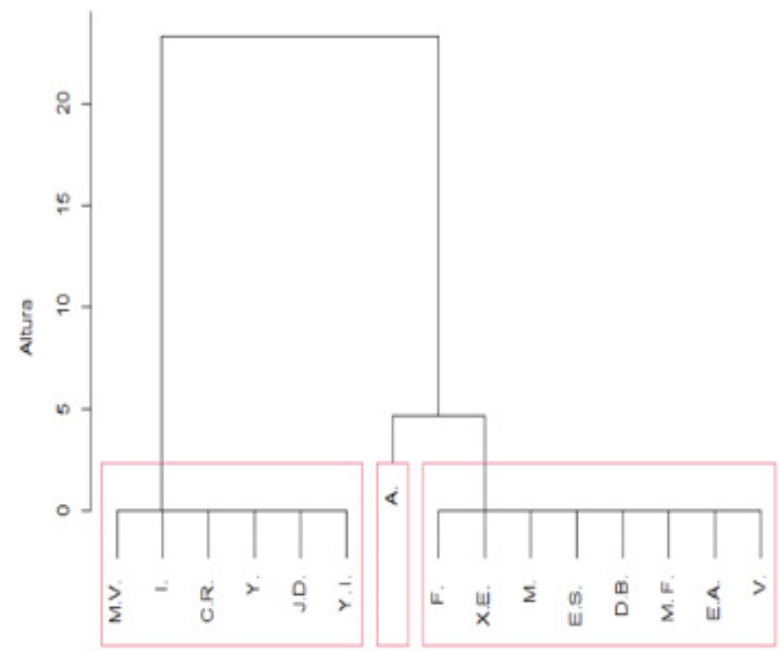

Alumnos

Nota. Se observa que se formaron tres grupos a una altura de dos. El grupo uno corresponde a los alumnos que tenían un nivel bajo. El grupo dos, el único alumno que tuvo un nivel alto y por último el grupo que tenía nivel medio. Respecto al cierre se obtuvo lo siguiente.
Figura 4

Dendrograma de nivel de lectura en voz alta al cierre.

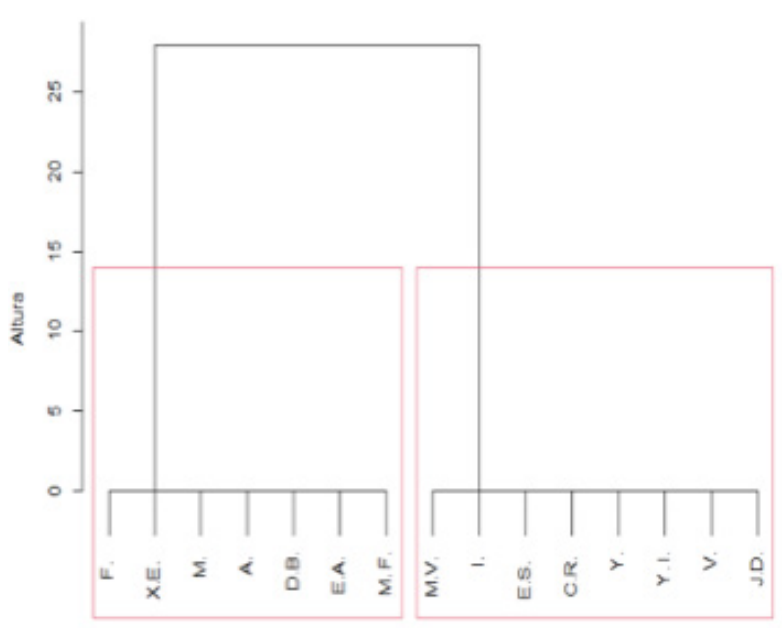

Nota. Se formaron dos grupos solamente a una altura de i3. El primer grupo corresponde a los alumnos que lograron un nivel alto y el segundo a un nivel medio. Con el club de lectura se logró eliminar el nivel bajo.

De acuerdo con la figura 5 en promedio el nivel al inicio fue de I.666, I 4 de los I5 alumnos tenían problemas para leer titubeaban o se atoraban, leían monótonamente, incluso quienes se mostraban nerviosos. Después de la intervención, in lograron subir de nivel. Cuatro se mantuvieron, tres de ellos porque no eran constantes en la asistencia y uno quedó en alto como estaba al inicio, pero en la práctica se observó más seguridad al leer. En promedio incrementaron al nivel 2.46. Es significativo mencionar que en la encuesta cierre los estudiantes señalaron que está fue la segunda actividad favorita con $30.76 \%$ de aceptación. 


\section{Figura 5}

Nivel de lectura en voz alta al inicio y al cierre de la intervención.

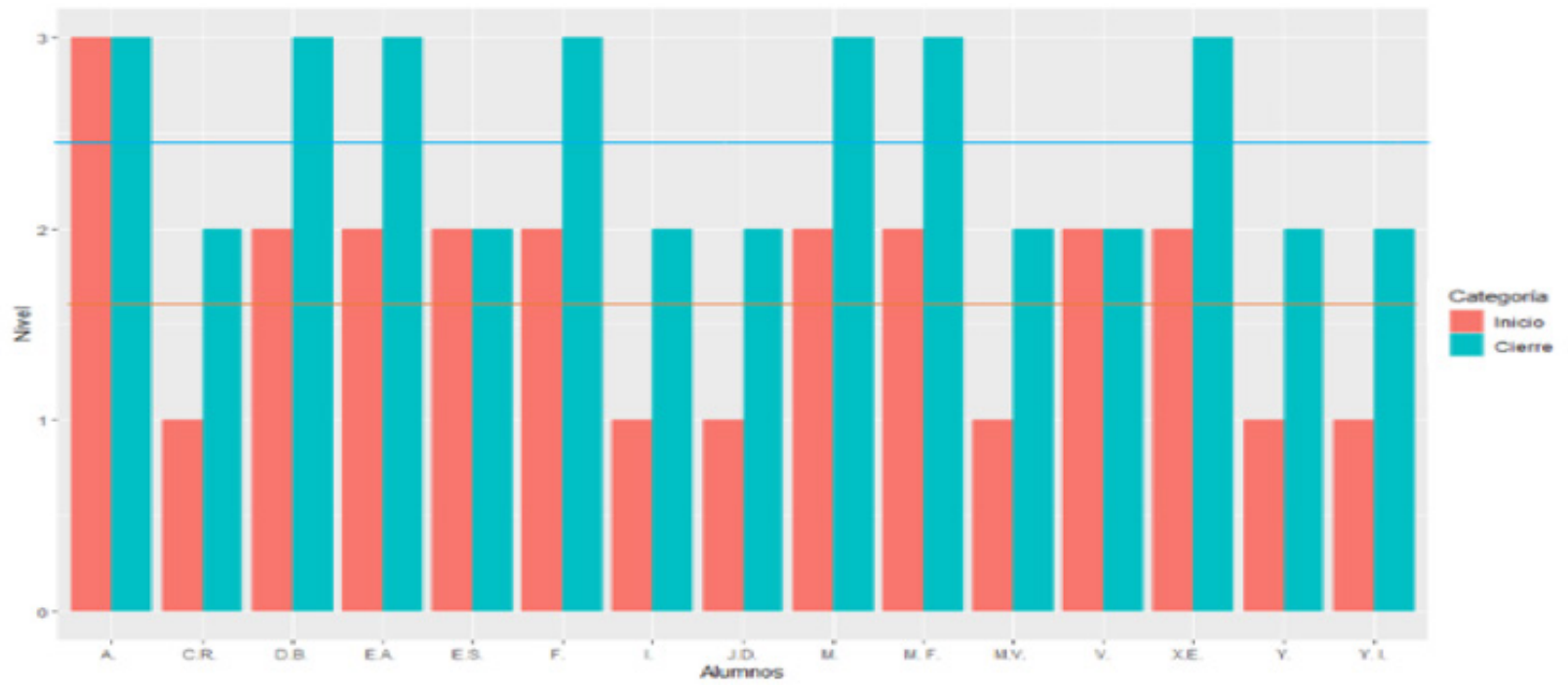

Nota. Se usaron las siguientes escalas: en el eje y (vertical) I: bajo, 2: medio, 3: alto. Con esto se trazaron 2 líneas la rosa indica el promedio del inicio que es i.666. La línea azul el promedio del cierre siendo 2.46. Estos indicadores nos dicen que hubo mejoría en la lectura. Por ejemplo, el alumno "I" tenía un nivel medio al inicio y al final tuvo nivel alto.

En el diagnóstico señalaron que las historias de su interés era principalmente la aventura, seguida de la ficción, el romance y de menor interés las de temas reales. A partir de esto, se les dio una lista de libros que podrían interesarles: Con los ojos abiertos, Hinojosa (20I5); Persona normal, Taibo (2OII); El libro salvaje, Villoro (2019); Ecos del desierto, Dubovoy (2007); Sombras en el arcoíris, Brozon. (2017) y El principio del placer, Pacheco (20I5) y ellos votaron por los dos libros que más les interesaba leer. De los cuales, los libros más votados y seleccionados para leer fueron Con los ojos abiertos (Hinojosa, 20I5) y Sombras en el arcoíris (Brozon, 2OI7). En la encuesta cierre justo estos dos libros se encontraban entre los tres libros favoritos, con el 50 \% de menciones Con los ojos abiertos (Hinojosa, 20I5) seguido del texto El almohadón de plumas con $25 \%$ (Quiroga, 2004) y el libro Sombras en el arcoúris con I2.5\% (Brozon, 20I7).

Durante las sesiones los estudiantes después de cada lectura realizaban comentarios de la obra y en sus respuestas podían externar sus pensamientos y emociones. En promedio por sesión casi Io alumnos expresaban juicios, sentimientos respecto a un texto. Luego de realizar la lectura individual y comentada en las reuniones, cada alumno decidió sobre qué libro realizaría su reseña si de la obra Con los ojos abiertos (Hinojosa, 20I5) o de Sombras en el arcoíris (Brozon, 20I7), también decidieron si iban a elaborar un video, audio o un texto digital. $\mathrm{El} 46.66 \%$ ( ( ) tuvo un nivel progresista en su análisis 
de la novela y comentarios, el 33.33\% (5) llegó a un nivel avanzado y sólo un 26.66 \% (3) realizó una reseña elemental, dos de ellas eran participantes asincrónicas y uno de ellos estaba en la mayoría de las sesiones y participaba pocas veces en lo escrito, siempre se mostraba tímido y sus comentarios muy concretos (Tabla 2).

\section{Tabla 2}

\section{Grupo con similitud de la reseña multimodal}

\begin{tabular}{|l|l|l|}
\hline Grupo & Nombre del alumno & Nivel \\
\hline 1 & M. & Avanzado \\
& Y.I. & \\
M.F. & E.A. & \\
& V. & \\
\hline 2 & M.V. & Novato \\
\hline 3 & J.D. & \\
\hline I. & Progresista \\
& F. & \\
& X.E. & \\
& E.S. & \\
& C.R. & \\
& Y. & \\
& D.B. & \\
& A. & \\
\hline
\end{tabular}

Nota. Se observa que el mayor grupo en cuanto a nivel fue el progresista. Sí hubo alumnos con un nivel novato siendo tres. El nivel avanzado tuvo mayor número respecto al novato.

Se realizaron actividades de creación literaria que, de acuerdo con la encuesta cierre, se colocó como la actividad favorita de los adolescentes. Se elaboraron finales alternativos, cuentos cooperativos, precuelas, microrrelatos, en los cuales podrían expresarse libremente, poner en práctica sus habilidades. Al inicio tuvieron bastantes dificultades de redacción para organizar sus ideas y pensamientos, no tenían coherencia ni cohesión, así como comprender las indicaciones. Aunque, con el tiempo lograron mejorar, de acuerdo con la rúbrica existían tres niveles de desempeño novato, progresista y avanzado. En la evaluación inicial el grupo de mayor número de alumnos tenían un nivel novato, es decir, ocho tenían un bajo desempeño al escribir, en el segundo grupo cinco contaban con nivel progresista y en el nivel avanzado sólo lograron dos estudiantes. (Figura 6). Es decir, había deficiencias entre los alumnos al redactar textos, tenían problemas de ortografía, coherencia y cohesión especialmente. Al concluir la intervención el nivel avanzado incrementó dos a ocho, el nivel progresista de cinco a seis alumnos y el nivel novato disminuyó de ocho a sólo un estudiante (Figura 7). 
En la figura 8, se usó I para indicar el nivel novato, 2 para nivel progresista y 3 para nivel avanzado. Con la línea azul se señaló el promedio del inicio de la intervención que fue de r.6 y con la línea rosa la media al cierre 2.46. Se observa que cada estudiante avanzó aproximadamente de un nivel a otro $73 \cdot 33 \%$ (II), mientras un I3.33\% (2) se mantuvo en nivel avanzado y I3.33 \% (2) se conservó, una de las participantes era en su mayor parte asincrónica y la otra sincrónica, pero no asistía siempre.

\section{Figura 6}

Dendrograma nivel de producción de textos narrativos al inicio.

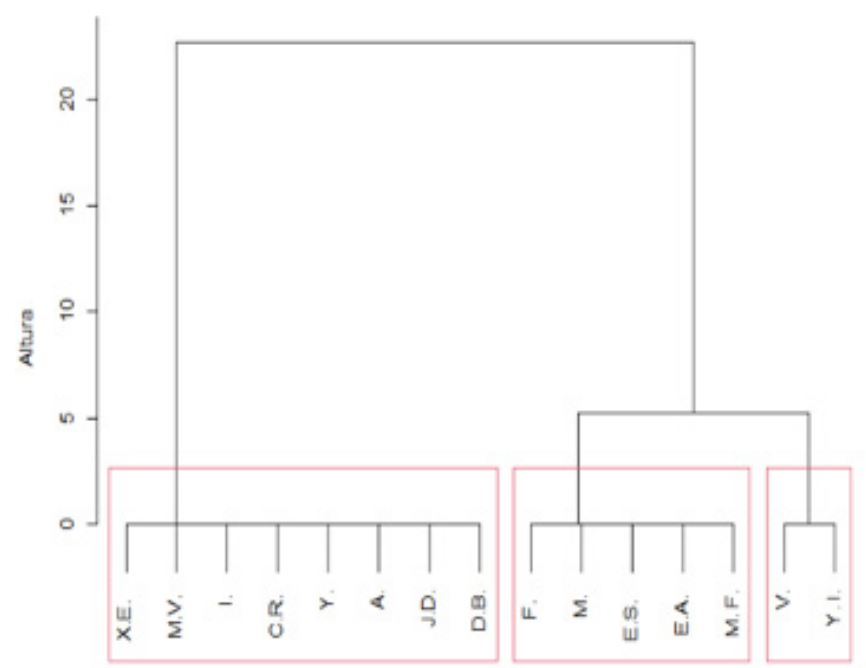

Alumnos

Nota. Representa los tres grupos que había al inicio. El de mayor número tenía un nivel novato, el segundo grupo nivel progresista y el ultimo avanzado. Es decir, había deficiencias entre los alumnos al redactar textos.

\section{Figura 7}

Dendrograma nivel de producción de textos narrativos al cierre.

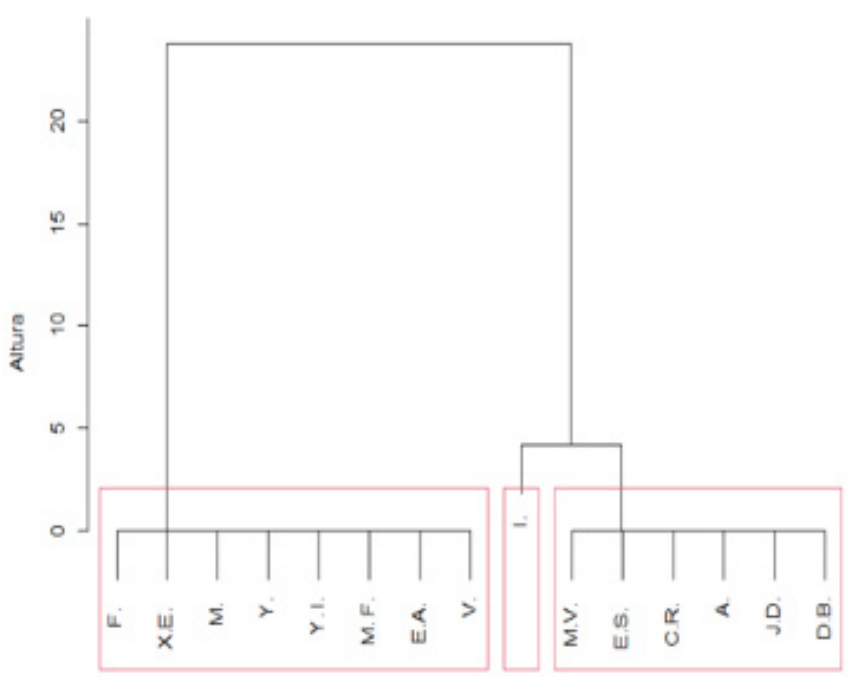

Alumnos

Nota. Se observa la formación de tres grupos a una altura de dos. El primer grupo obtuvo un nivel avanzado siendo este el más grande en cuanto a número de alumnos. También se muestra que el tercer grupo llegó a un nivel progresista. 


\section{Figura 8}

Comparativo de nivel de producción de textos narrativos al inicio y al cierre.

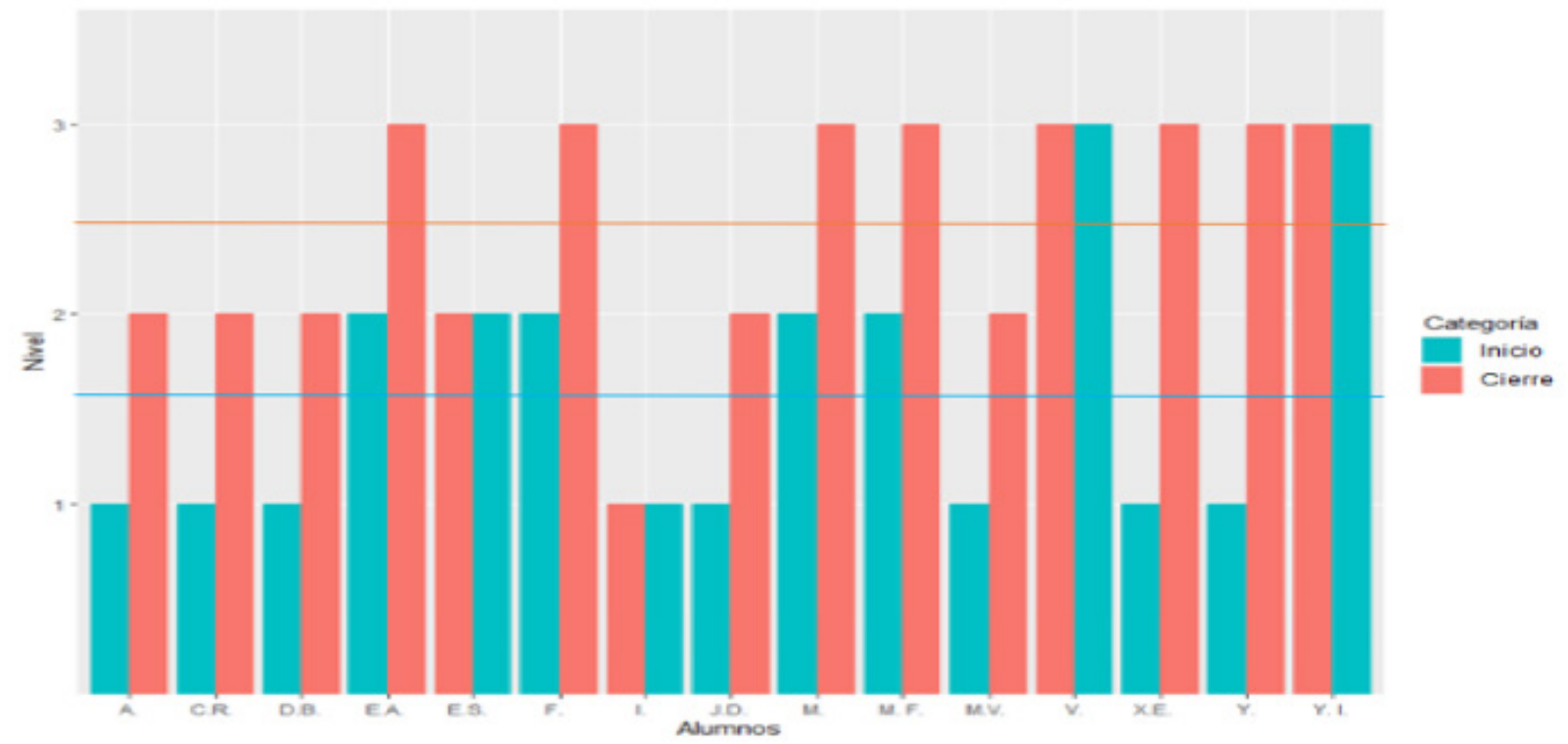

Nota. Se usaron las siguientes escalas: en el eje y (vertical) I: novato, 2: progresista, 3 : avanzado. Con esto se trazaron 2 líneas, la azul indica el promedio del inicio que es i.6. La línea rosa el promedio del cierre 2.46 en promedio. Estos indicadores nos dicen que hubo mejoría en la producción de textos. Por ejemplo, el alumno "M" tenía un nivel progresista al inicio y al final tuvo nivel avanzado.

\section{Conclusiones}

La propuesta de modalidad virtual es factible para realizar promoción de lectura entre adolescentes ya que es un medio atractivo que permite una narrativa multimodal, así como interacción directa e indirecta, a pesar de que existan problemas de conexión de la red. Facebook se consolidó como el principal canal sincrónico y asincrónico a través del cual se realizaban transmisiones en vivo de la lectura en voz alta y trabajo de escritura creativa. Mientras Zoom fue usado para el diálogo directo de los libros seleccionados y leídos previamente a la reunión, así como algunas lecturas en voz alta, WhatsApp fue usado como un canal de comunicación y generador de vínculos de confianza entre alumnos y promotora, a través de esta plataforma se podían compartir algunos textos o ligas, videos y avisar si había algún cambio, si tenían un problema o no ponían conectarse.

Es necesario considerar que la planeación es una brújula para el investigador, para saber qué pretende realizar y cómo lograrlo; no obstante, es relevante saber que ésta no es rígida, sino flexible y adaptable a las circunstancias que se presenten durante 
la intervención. Así como a los gustos, intereses y necesidades del grupo intervenido. En el caso de esta iniciativa con adolescentes los autores de literatura juvenil que más les agradaron a los estudiantes fueron Francisco Hinojosa y Mónica Brozon, mientras que sus escritores preferidos de lecturas clásicas juveniles fueron Horacio Quiroga, Julio Cortázar, Óscar Wilde.

Para futuras intervenciones, se recomiendan que el club de lectura sea tres veces a la semana y se asigne por día una diferente actividad para no caer en la monotonía. En cuanto a los textos para adolescentes se sugiere que el investigador esté al día de las propuestas literarias más recientes, que sea interesantes, de corte iniciático y de preferencia protagonizadas por personajes entre i6 y máximo I8 años, ya que si son jóvenes mayores de 18 se pierde un poco el interés. Además, se debe tener cuidado de no caer en obras literatura industrial y también se aconseja solicitar trabajos a través audios en vez de videos, especialmente si son menores. Finalmente, sería interesante integrar una o dos actividades en las cuales los padres de familia se involucren en el proceso de lectura de sus hijos. 


\section{Referencias bibliográficas}

- Amar, V., Romero, M., y Heredia, H. (20I8). Facebook, un espacio para compartir la lectura. Una experiencia en un aula de Educación Obligatoria Secundaria en España. Educação em Foco, 23 (I), 2OI-224. Obtenido el I8 de mayo de 2020 desde https://periodicos.ufjf.br/ index.php/edufoco/article/view/r9989.

-Antunes, C. (2007). Vygotsky en el aula ¿quién lo diría? Buenos Aires: Sb.

- Bibbó, M. (2018). La lectura en tiempos de Facebook. Catalejos. Revista sobre lectura, formación de lectores y literatura para niños, 3(6), 203-2I6. Obtenido el I9 de mayo de 2020 desde http://fh.mdp.edu.ar/revistas/index.php/catalejos/article/view/2764.

- Brozon, M. B. (20I7). Sombras en el arcoíris. México: Fondo de Cultura.

- Cassany, D. (20I3). Tras las líneas: sobre la lectura contemporánea. España: Anagrama.

- Cassany, D. (2016). En_línea. Leery escribir en la red. México: Anagrama.

- Cerrillo Torremocha, P. C. (2005). Los nuevos lectores; la formación del lector literario. Literatura infantil y educación literaria, I33-I52. Obtenido el $\mathrm{I} 8$ de mayo de 2020 desde https://www.biblioteca.org.ar/libros/ı34288.pdf

- Cerrillo Torremocha, P. C. (20I5). Sobre la literatura juvenil. Verba Hispánica, 23(I), 2II228. https://doi.org/IO.43I2/vh.23.I.2II-228.

- Colasanti, M. (2OII). Fragatas para tierras lejanas, conferencias sobre literatura (E. Obregón trad.). México: Norma. (Original publicado en 2004).

- De la Cruz González-Cutre, I. y Saurin Parra, J. (20I3). Los clubes de lectura en la era digital. Pasado, presente y futuro. VI Congreso Nacional de Bibliotecas públicas: memoria individual, patrimonio global, 35-358. Obtenido el I8 de mayo de 2020 desde http://travesia. mcu.es/portalnb/jspui/bitstream/IO42I/6746/I/clubes_lectura.pdf

- Díaz Rosero, Y. (20I9). Memes, podcast y formato booktuber, otras formas de lectura y escritura. Revista Ideales, 8. Obtenido el I8 de mayo de 2020 desde http:// 45·7. I.7.I5/index. php/Ideales/article/viewFile/ı879/I458.

- Diel Schanzembach, M. (2019). Lecturas, pantallas y adolescentes lectores. [Tesis de maestría, Universidad ORT Uruguay]. Repositorio Institucional Universidad ORT Uruguay. Obtenido el I8 de mayo de 2020 desde http://hdl.handle.net/20.5Oo.II968/40I9.

- Dubovoy, S. (2007). Ecos del desierto. México: Fondo de Cultura Económica. 
- Ferrándiz Soriano, J. U. (2OI4). Clubes de lectura virtuales: el modelo por videoconferencia. TEJUELO: Revista de ANABAD-Murcia, ı3, 26-35. Obtenido el 18 de mayo de 2020 desde https://dialnet.unirioja.es/servlet/articulo?codigo= ${ }^{2}$ I5446.

- Fraire, P. (2005). Pedagogía del oprimido (J. Mellado trad.). México: Siglo veintiuno.

- García Aretio, L. (2008). Diálogo didáctico mediado. España: Editorial del BENED.

- García Figueroa, A. M. (2016). Promoción de lectura mediante Facebook entre estudiantes de la Facultad de Contaduría de la Universidad Veracruzana campus Ixtaczoquitlán. [Protocolo de la Especialización en Promoción de la Lectura, Universidad Veracruzana]. Repositorio Institucional Universidad Veracruzana. Obtenido el I9 de mayo de 2020 desde https:// www.uv.mx/epl/files/20I5/o8/Reporte_AgeluzMelissaGarciaFiguero_o8o3ı6.pdf

- Garrido, F. (20I4). Para leerte mejor. Mecanismos de la lectura y de la formación de lectores capaces de escribir. México: Paidós.

- Garrido, F. (20I9). El buen lector se hace, no nace. Reflexiones sobre la escritura y la lectu$r a$. México: Paidós.

- Hinojosa, F. (20I5). Con los ojos abiertos. México: Fondo de Cultura Económica.

- Instituto Nacional de Estadística y Geografía (INEGI). (2020). Módulo sobre Lectura (MOLEC). Principales resultados. INEGI. Obtenido el og de marzo de 2020 desde https:// www.inegi.org.mx/contenidos/programas/molec/doc/resultados_molec_feb2o.pdf

- López Acosta, S. A. (20I5). Promoción de la lectura en espacios virtuales: el caso del portal de lectores y lecturas de la UV. [Trabajo recepcional, Especialización en Promoción de la Lectura, Universidad Veracruzana]. Repositorio Institucional Universidad Veracruzana. Obtenido el I9 de mayo de 2020 desde https://cdigital.uv.mx/bitstream/handle/ı23456789/4I565/LopezAcostaSergio.pdf;jsessionid==18F 3455B9oE9ı6CoDı4D669F $8 \mathrm{C}_{4} \mathrm{E}_{2} \mathrm{~A}_{7}$ ? sequence $=2$

- Lluch, G. (20I4): Análisis de narrativas infantiles y juveniles. España: Ediciones de la Universidad de Castilla-La Mancha.

- Moral, A., y Arbe, U. (2OI3). Una experiencia docente sobre la lectura compartida, la lectura por placer y las TICS como medio de comunicación y creatividad: Club de Lectores. Psicología educativa, I9(2), I23-I26. https://doi.org/ı.IOI6/SII35-755X(I3)700I9-8

- Pacheco, J. E. (20I5). Elprincipio del placer. México: Ediciones Era.

- Prieto García, J. A. (20Iо). Efectividad de las herramientas de la web social en un club de lectura. El caso del Club de Lectura El Grito. Biblioteca pública y contenidos digitales: 
retos y oportunidades, 3II-3I7. Obtenido el I7 de mayo de 2020 desde http://hdl.handle. net/IO42I/554I .

- Puc Domínguez, L. (2015). Adolescentes lectores: promoción de la lectura entre estudiantes de tercer grado de secundaria en Coscomatepec, Veracruz [Protocolo de la Especialización en Promoción de la Lectura, Universidad Veracruzana]. Repositorio Institucional Universidad Veracruzana. Obtenido el I7 de mayo de 2020 desde https://www.uv.mx/epl/ files/20I5/o8/Protocolo-Laura-Puc-Dominguez.pdf

- Quiroga, H. (2004). El almohadón de plumas. En Cuentos de amor locura y muerte (pp.576o). México: Ediciones leyenda.

- Rodríguez, F. (20I3). La noción de género literario en la teoría de la recepción de Hans Robert Jauss. Revista Comunicación, II(2). Obtenido el I5 de junio de 2020 desde https:/ / revistas.tec.ac.cr/index.php/comunicacion/article/view/I274/II77.

- Salinas, D., De Moraes, C. y Schwab, M. (20I9). Programa para la Evaluación Internacional de Alumnos (PISA). México - Nota país - Resultados PISA 2018, II-III, I-I2. OCDE. Obtenido el Io de marzo de 2020 desde https://www.oecd.org/pisa/publications/PISA2OI8_ CN_MEX_Spanish.pdf

- Samperio, G. (20I6). La señorita Green. En F. Rodríguez Criado, Narrativa breve. Obtenido el I4 de junio de 2020 desde https://narrativabreve.com/2OI6/ı2/cuento-corto-deguillermo-samperio-la-senorita-green.html

- Sánchez Sosa, E. R. (20I8). Taller de lectura virtual para empleados profesionales de la Universidad Veracruzana [Protocolo de Especialización en Promoción de la Lectura, Universidad Veracruzana]. Repositorio Institucional Universidad Veracruzana. Obtenido el I5 de junio de 2020 desde https://www.uv.mx/epl/files/20I8/o9/4._Protocolo_Erika_Sanchez_Autorizado.pdf

- Sánchez Vázquez, A. (2005). Segunda conferencia: La Estética de la Recepción (I). El cambio de paradigma (Robert Hans Jauss). Repositorio de la Universidad Iberoamericana León. Obtenido el I5 de junio de 2020 desde https://repositorio.leon.uia.mx/xmlui/IO39I/I843 .

- Solé, I. (2009). Estrategias de lectura. España: Grao.

- Taibo, B. (2OII). Persona normal. México: Editorial Destino.

-Villoro, J. (20I9). El libro salvaje. México: Fondo de Cultura Económica. 